\title{
The role of adiponectin receptors in the regulation of synaptic transmission in the hippocampus
}

Filippo Weisz ${ }^{1,2 *}$, Sonia Piccinin ${ }^{1,2}$, Dalila Mango ${ }^{1,2}$, Richard Teke Ngomba ${ }^{3}$, Nicola B. Mercuri ${ }^{4}$, Ferdinando Nicoletti ${ }^{2,5}$, Robert Nisticò ${ }^{1,4}$

${ }^{1}$ Department of Pharmacology of Synaptic Plasticity Lab, Fondazione EBRI-Rita Levi Montalcini, Rome, Italy

2 Vittorio Erspamer Departement of Physiology and Pharmacology, University of Rome "La Sapienza", Rome, Italy

${ }^{3}$ School of Pharmacy, University of Lincoln, Lincoln, UK

${ }^{4}$ University of Rome "Tor Vergata", Rome, Italy

${ }^{5}$ IRCCS Neuromed, Pozzilli, Italy.

* Correspondence:

Filippo Weisz, Fondazione EBRI-Rita Levi Montalcini, Rome, Italy

Phone: +39 0650170 3024; Fax: + 390650170 3335; email: f.weisz@ebri.it

\begin{abstract}
In the last two decades adiponectin, member of the adipokines family, gained attention because of its unique antidiabetic effects. However, the presence in the brain of adiponectin receptors and adiponectin itself raised interest because of the possible association with neuropsychiatric diseases. Indeed, clinical studies found altered concentration of adiponectin both in plasma and cerebrospinal fluid in seeveral pathologies including depression, multiple sclerosis, Alzheimer's disease and stroke. Moreover, recent preclinical studies also suggest its involvement in different physiological functions. Despite this evidence very few studies attempted to elucidate the functional role of adiponectin at the synapse.To address this question, here we investigated the effect of Adiporon, an agonist of both adiponectin receptors on synaptic transmission and LTP at Schaffer-collateral CA1 pathway. Surprisingly, increasing concentration of Adiporon correlated with lower CA1-LTP levels and paired-pulse ratio, whereas basal transmission was always preserved. Collectively, our data show that the adiponectin system, beyond its involvement in metabolic diseases, plays also a critical role in synaptic activity thereby representing a putative target for the treatment of synaptic pathologies.
\end{abstract}

Key words: Adiponectin, synaptic plasticity, hippocampus, Long Term Potentiation, electrophysiology, Adiporon 


\section{INTRODUCTION}

Adiponectin, a member of the Adipokine family, has sparked new enthusiasm in the field of metabolic diseases and paved the way for a new generation of drugs affecting metabolism (Okada-Iwabu et al., 2015). In fact, a key role of adiponectin in several metabolic and inflammatory disorders has recently emerged. Accordingly, plasma adiponectin levels were found decreased in obesity, insulin resistance, and type 2 diabetes (Kadowaki et al., 2006). Moreover, adiponectin exerts a protective role in several pathologies, such as cardiovascular diseases, cancer, and appears also to promote longevity (Yamauchi and Kadowaki, 2013). However, after the discovery of adiponectin in human cerebrospinal fluid (Kos et al., 2007), the adiponectin system gained attention and several clinical studies suggested a role in neuropsychiatric diseases, such as depression (Leo et al., 2006; Narita et al., 2006), cognitive impairment associated with diabetes (Masaki et al., 2012; Gorska-Ciebiada et al., 2015), Alzheimer's disease (Teixeira et al., 2013), stroke (Sasaki et al., 2007), multiple sclerosis (Musabak et al., 2010) and attention deficit hyperactivity disorder (Mavroconstanti et al., 2014). In particular, those studies have all reported lower circulating levels of adiponectin. Adiponectin is an adipocyte-derived polypeptide released into the circulation in the configuration of full-length trimers, hexamers, high molecular weight (HMW) multimers and a globular fraction called globular adiponectin ( $g A D)$, generated by proteolytic cleavage of the full-length protein (Waki et al., 2005). Surprisingly this protein is one of the most abundant, representing $0.05 \%$ of total plasma proteins (Scherer et al., 1995). Adiponectin exerts its effects by binding three receptors. Two of them, adipoR1 and adipoR2, are integral membrane proteins with seven transmembrane domains (7TM). However, these receptors possess an intracellular amino terminus and an extracellular carboxyl-terminus which renders them a novel structural class (Tanabe et al., 2015). The third receptor is T-cadherin which is also an LDL receptor. The transduction pathways of adipoR1 and 2 culminate in the activation of AMPK and PPAR $\alpha$ while T-cadherin acts in an unknown way (Wang and Scherer, 2016). Despite mounting evidence of adiponectin involvement in many neuropsychiatric diseases which show a synaptic pathology (Ganguly and Poo, 2013), their physiological role in the synapse remains elusive. One experimental difficulty could be represented by the fact that, for the majority of relevant functions, both the principal receptors must be activated simultaneously (Yamauchi et al., 2007). On other hand, adipoR1 and 2 show divergent Kd values for different adiponectin forms (Yamauchi and Kadowaki, 2013). As the receptors are highly expressed in hippocampus (Repunte-canonigo et al., 2011; Thundyil et al., 2012) we employed a selective agonist for adipoR1 $\backslash 2$ (Adiporon, ADPO) with similar Kd values for both receptors(Okada-Iwabu et al., 2013). In this way, we were able to activate simultaneously both receptors and study their functional role in synaptic transmission and neuroplasticity at CA1 hippocampal synapses.

\section{MATERIALS AND METHODS}

\section{Animals}

Experiments were carried out in accordance with the guidelines established by the European Communities Council (Directive 2010/63/EU of 22 September 2010) and accepted by the Italian Ministry of Health (D.Lgs. 26/2014) and approved by the Ethical Committee on animal experiments of Santa Lucia Foundation (Rome, Italy). Two- to four-week-old male C57BL/6J mice (Young group) and five-to eight-week-old male C57BL/6J mice (Adult group) were used for all experiments. 


\section{Electrophysiology}

Preparation of mouse brain slices was performed as previously described (Nisticò et al., 2013). Parasagittal hippocampal slices (thickness, 250-350 $\mu \mathrm{m}$ ) were cut using a Vibratome (Leica VT1000 S) and incubated for $1 \mathrm{~h}$ in a holding chamber and then transferred to a recording chamber, completely submerged in artificial cerebrospinal fluid (ACSF, $30-31^{\circ} \mathrm{C}$ ) of the following composition (in $\mathrm{mM}$ ): $\mathrm{NaCl}(124), \mathrm{KCl}(3), \mathrm{MgCl} 2(1)$, $\mathrm{CaCl} 2$ (2), NaH2PO4 (1.25), $\mathrm{NaHCO} 3$ (26), glucose (10); saturated with 95\% O2, 5\% CO2. For extracellular recordings, bipolar stimulating electrode was placed in the stratum radiatum to activate the Schaffer collateral commissural fibers. Recordings of field excitatory postsynaptic potentials (fEPSPs) were made in the middle of the stratum radiatum by using microelectrodes filled with ACSF (resistance 3-5 M 2 ). For slices in which the presynaptic fiber volley was distinguishable, input-output curves were examined by plotting the initial slope of the fEPSP against the amplitude of the presynaptic fiber volley. Long-term potentiation (LTP) was induced by high-frequency stimulation (HFS; $100 \mathrm{~Hz}$, duration $1 \mathrm{~s}$ ).

\section{Drug Treatments}

Adiporon (ADPO; Sigma) was dissolved in dimethyl sulfoxide (DMSO), prepared as stock solutions and diluted to the final concentration immediately before use. Final concentrations were as follows: ADPO (1.5, $3,30 \mu \mathrm{M})$. DMSO was used both in treated and in vehicle groups and the final concentration of DMSO was less than $0.5 \%$ in all experiments. Incubation of hippocampal slices with drugs was performed in an incubation chamber. The pre-incubated treated and vehicle slices were held in ACSF with or without several concentration of ADPO for 1.5-2 hours before recordings.

\section{Statistical Analysis}

For statistical analysis we used unpaired t test after LTP induction (on the average of the last 10 min of recording). The overall depolarization during HFS has been quantified using a slightly modified method (Kuenzi et al., 2000) by measuring the area under the curve (AUC) during the $100 \mathrm{~Hz}$ train stimulus using as $y$ value the baseline and normalising each obtained AUC to the first fEPSP in each train. All data are presented as mean \pm SEM, and " $n$ " indicates the number of slices. $P<0.05$ was considered significant.

\section{RESULTS}

\section{Adiporon affects paired pulse ratio but does not influence basal synaptic transmission}

After 20 min of stable baseline recordings, consecutive application of increasing concentrations of ADPO $(1.5,3,30 \mu \mathrm{M})$ for 15 minutes did not modify basal synaptic transmission (data not shown). In a subset of experiments, we delivered a tetanic stimulation to Schaffer collaterals $(100 \mathrm{~Hz}, 1 \mathrm{sec}$ ) following perfusion of ADPO. Although some increase in LTP magnitude was present, it did not reach statistical significance (data not shown). Since adiponectin receptors display a slow activation rate upon agonist exposure on a time scale of minutes to hours (Qiu et al., 2011; Song et al., 2013; Shah et al., 2014), we then evaluated ADPO effects after pre-incubating slices for 2 hours with increasing concentrations (1.5, 3, $30 \mu \mathrm{M})$. ADPO effect was always evaluated in hippocampal slices from young (two- to four-week-old) and adult (five- to eightweek-old) male C57BL/6J mice, since the mechanisms underlying synaptic transmission differ at the two age stages (Lohmann and Kessels, 2014). We then performed a paired pulse ratio (PPR) protocol to assess the paired pulse facilitation, which represents a form of short-term plasticity that occurs through presynaptic mechanisms and mirrors presynaptic release probability (Zucker and Regehr, 2002). A decrease 
in the PPR was present when ADPO was perfused at the concentration of $30 \mu \mathrm{M}(\mathrm{p}<0.05$ at all intervals; fig.1A,B) suggesting an increase in the release probability in both experimental groups. However, at the concentration of 1.5 and $3 \mu \mathrm{M}$, ADPO did not significantly modify the PPR ( $p>0.05$; fig.1A,B). Next, we performed an input-output curve analysis to investigate whether the reduction in PPR was accompanied by some changes in basal excitatory transmission. Surprisingly, none of tested concentrations of ADPO $(1.5,3$, $30 \mu \mathrm{M})$ significantly affected the input-output curve at both ages groups ( $p>0.05 ;$ fig.1C,D). The latter data suggest that, despite a change in PPR at the highest ADPO tested concentration ( $30 \mu \mathrm{M})$, the amplitude of fEPSPs was always preserved.

\section{Dose-dependent effect of Adiporon on CA1-LTP}

Following the investigation on the effects of ADPO on PPR and baseline transmission, we next evaluated LTP, a widely recognized model that underlies the synaptic basis of memory (Bliss and Collingridge, 1993). In a subset of experiments hippocampal slices were pre-incubated for 2 hours with different concentrations of $\operatorname{ADPO}(1.5,3,30 \mu \mathrm{M})$ and after obtaining a stable baseline, we delivered HFS protocol to Schaffer collaterals. Both age groups showed a marked reduction in LTP at the highest tested concentration of ADPO $(30 \mu \mathrm{M})$ (fig.2A,B). However, the young age-group seemed less prone to ADPO's dampening effect on LTP compared to the adult group. Indeed, in the young group, meanwhile we still find a strong effect of ADPO on the PPR, the ADPO's capability to inhibit LTP was low at the highest tested concentration ( $30 \mu \mathrm{M})$ (vehicle $47 \pm 4 \%$ vs. ADPO $24 \pm 4 \%, p<0.05$; fig.2A) and tended to decrease at a lower concentration ( $3 \mu \mathrm{M}$ ) (vehicle $47 \pm 4 \%$ vs. ADPO $44 \pm 3 \%, p>0.05$; fig2A), until no inhibitory effect on LTP was observed at $1.5 \mu \mathrm{M}$ ( $p>0.05$, data not shown). On the other hand, in the adult age-group, at the highest tested concentration of ADPO $(30 \mu \mathrm{M})$, LTP was almost abolished (vehicle $46 \pm 2 \%$ vs. ADPO $7 \pm 3 \%, p<0.01$; fig.2B). This effect faded with lower concentrations with a reduction of LTP of approximately $50 \%$ at $3 \mu \mathrm{M}$ (vehicle $46 \pm 2 \%$ vs. ADPO $21 \pm 2 \%, p<0.05$; fig.2B), until it disappeared at $1.5 \mu \mathrm{M}$ ( $p>0.05$, data not shown). Notably, in the adult age-group, meanwhile the dampening effect on LTP was concentration-dependent, the reduction in PPR was apparent only at higher concentration $(30 \mu \mathrm{M})$. Moreover, ADPO concentration of $3 \mu \mathrm{M}$, that still maintained an inhibitory effect on LTP in Adult group, was not able to affect the PPR in adult neither in young animals.

\section{Adiporon affects field excitatory post synaptic potential during tetanic stimulation}

Although basal synaptic transmission was never affected by increasing concentrations of ADPO in both agegroups, we noticed an interesting alteration of fEPSP during tetanus in adult hippocampal slices preincubated with increasing concentrations of ADPO. Notably, fEPSPs amplitude elicited by a high frequency tetanic stimulation decreased earlier in slices treated with several ADPO concentrations $(1.5,3,30 \mu \mathrm{M})$ compared to control (fig.2C). Thus, we decided to further investigate the ability of ADPO to modulate fEPSP during the high frequency tetanic stimulation, which is known to induce in neurons a strong level of depolarization which depends on calcium influx (Herron et al., 1986). To this aim, we utilized a modified method of analysis (Kuenzi et al., 2000), we measured the AUC (area under the curve) normalised to the first fEPSP in each train. This method allows to quantify the level of depolarization of the post-synaptic cell during the HFS train which is correlated to the extent of LTP amplitude (Bliss and Collingridge, 1993). Unlike paired pulse facilitation, the attenuation of depolarization during HFS was concentration dependent and correlated to the degree of LTP attenuation ( $p>0.05$ at all tested concentrations vs. vehicle; fig. $2 C$ ). The concentration-dependent effect of ADPO on AUC reduction matched the inhibitory effect on LTP and 
strongly suggests that ADPO might exert an effect also through a post-synaptic mechanism. Taken together, these data suggest that ADPO influenced PPR and LTP through different synaptic mechanisms.

\section{DISCUSSION}

In recent years, adiponectin gained attention in several physiological conditions such as hormonal release (Wen et al., 2008; Hoyda et al., 2009; Hoyda and Ferguson, 2010; Mimee et al., 2013), feeding behavior (Qi et al., 2004) and neurogenesis (Yau et al., 2014). In addition, preclinical studies pointed out a role in brain disorders including depression (Yau et al., 2014), Alzheimer's disease (Chan et al., 2012; Ali et al., 2015), stroke (Song et al., 2013), fear learning (Zhang et al., 2016b) and epilepsy (Lee et al., 2011). These pathologies share, to different degrees, a disruption in synaptic plasticity (Ganguly and Poo, 2013). For these reasons, we have here investigated whether and how adiponectin receptors activation could influence synaptic transmission and plasticity in normal conditions.

Adiponectin is released in a unique fashion since it is the only protein that increases with weight loss (Wang and Scherer, 2016). However, it has been suggested that adiponectin plasmatic level could increase also with chronic and acute physical activity (Vuolteenaho et al., 2014). Once adiponectin reaches the circulation, it could pass, at least in the trimeric form, the blood-brain barrier (Kusminski et al., 2007; Yau et al., 2014). On other hand adiponectin mRNA has been repeatedly detected in central nervous system (Rodriguez-Pacheco et al., 2007; lannitti et al., 2015). Thus, central nervous system could have the competence to locally produce and release adiponectin, although it is not clear whether this protein acts locally or rather its effect might influence larger numbers of cells and cerebrospinal fluid content. However, it is well recognized that both adiponectin receptors are highly expressed in different brain areas; in particular the hypothalamus, thalamus, neocortex and hippocampus (Repunte-canonigo et al., 2011; Yau et al., 2014).

In this study we provide the first compelling evidence that a ADPO, a selective agonist for AdipoR1 $\backslash 2$ is able to influence synaptic plasticity in CA1 hippocampal region in a concentration-dependent fashion. Importantly, the dampening effect on LTP was mirrored by a reduction of responses during high frequency stimulation despite a preserved basal synaptic transmission.We assume that the concentration-dependent dampening effect on LTP relies, mostly, on a post-synaptic mechanism. Indeed, we found a strong decrease of fEPSP during the high frequency stimulation protocol that closely mirrors the concentration-dependent reduction of LTP. The induction of LTP depends critically on the depolarization of the pyramidal cells, that is a function of both excitatory synaptic connections and local GABAergic inhibitory connections (Bliss and Collingridge, 1993). The failure to induce LTP does not seem due to lack of excitatory drive as revealed from input-output curve. The alteration in PPR could also suggest a presynaptic mechanism but, as aforementioned, ADPO effect on paired pulse facilitation was present only at the highest tested concentration $(30 \mu \mathrm{M})$. During the HFS the cell is heavily depolarized, therefore the more attractive candidate, which might be influenced by adiponectin receptor activation, is the NMDA receptor because of its voltage-dependency. This hypothesis is supported by the reduced efficacy of ADPO observed in younger mice that could mirror a developmental change in NMDA receptor subunit expression (Monyer et al., 1994). Noteworthy, all the above features summarize many of the effects of the NMDA receptor antagonists. Indeed, as previously shown in several studies (Herron et al., 1986; Frankiewicz et al., 1996; Ribeiro et al., 2014), when NMDA receptor are blocked, the outcome is, invariably, a dampening of high frequency responses, mirrored by a reduction in LTP. Moreover NMDA receptor antagonists such as ketamine, MK-801, APV, 7-chlorokynurenic acid, induce an age-dependent (Nosyreva et al., 2014) and rapid 
(e.g. 2h) BDNF expression and synaptogenesis (Li et al., 2010; Autry et al., 2011; Gideons et al., 2014; Li et al., 2016). In line with this, a recent report showed that intracerebroventricular injection of adiponectin increases synapse number and dendritic complexity in hippocampus (Zhang et al., 2016a). Finally, another report suggested a role for adiponectin in the response rate to ketamine in a depressed patient (MachadoVieira et al., 2016).

Thus, ADPO seems to recapitulate many of the electrophysiological features of NMDA receptors blockers, thus it might also represent an agent with antidepressive properties like adiponectin itself or several NMDA receptors blockers.

An alternative explanation could be that ADPO induces an initial hyperpolarization of the pyramidal neurons that in turn inhibit the activation of NMDAR during HFS. This hypothesis is consistent with a recent report about ADPO effect on granule cells of dentate gyrus where this drug caused an hyperpolarization of the resting membrane potential (Zhang et al., 2016b). Here we report that ADPO reduces also the paired pulse ratio, an effect that could originate from the change of some presynaptic conductances. In line with this, Hoyda and collegues, observed sustained outward potassium current elicited by adiponectin in hypothalamic neurons. This TEA-sensitive current was able to broaden the action potential (Hoyda and Ferguson, 2010). In turn, action potential broadening has, via BK channels, a strong effect on synaptic terminals where it can dramatically increase the probability of neurotransmitter release (Deng et al., 2013). At the single neuron level, adiponectin receptors activation can either have an excitatory, inhibitory effect or neither of two (Hoyda et al., 2009; Hoyda and Ferguson, 2010; Repunte-canonigo et al., 2011). However, Osmotin, a natural agonist of adiponectin receptors seems to have an important protective role against memory impairment in an Alzheimer's model mice (Ali et al., 2015). This effect is consistent with the protective role of adiponectin in cells which overexpressed amyloid-beta (Chan et al., 2012). Indeed, despite their wide range of electrophysiological effects, adiponectin receptors mediate a protective role in several in vitro (Qiu et al., 2011; Shah et al., 2014) and in vivo (Nishimura et al., 2008; Jeon et al., 2009;Lee et al., 2011; Song et al., 2013) disease paradigms. Interestingly, in some of these studies its protective effect seems to be mediated by an active preservation of synaptic integrity that relies on AMPA receptor trafficking (Shah et al., 2014; Ali et al., 2015). Thus, it is feasible that many of the beneficial effects could be mediated by complex synaptic changes that account also for more general effects, e.g., decreasing severity seizure in mice model of epilepsy (Lee et al., 2011).

In summary, our main finding is a strong reduction of LTP with the highest tested concentration of $A D P O$,albeit the potential mechanisms underlying this effect remains to be investigated. Certainly, data here presented suggest for the first time that the adiponectin system, beyond its implication in metabolic and inflammatory diseases, plays also a central modulating role at the synapse thereby representing a novel target for the treatment of brain diseases. Importantly, in all aforementioned pathologies, patients showed a reduction of serum levels of adiponectin. On the other hand, preclinical evidence strongly suggests that increased glutamatergic transmission is a key feature of the above diseases models (Gleichmann et al., 2012; Popoli et al., 2012; Casillas-Espinosa et al., 2012; Chao and Li, 2014; Mandolesi et al., 2015). Although further experiments are needed to investigate possible detrimental effects of adiporon, our data suggest that a replacement therapy with adiponectin or adiporon could have an important impact on synaptic function in several pathologies. 


\section{Acknowledgments}

This research was partly supported by from the Italian Ministry of Health to IRCCS National Neurological Institute "C. Mondino" (Ricerca Corrente).The authors sincerely acknowledge Dr. Nicola Berretta for the pivotal advices during the data analysis.

\section{Author Contributions}

FW and SP performed experiments. FW, RTN, NM, FN and RN designed research. FW and DM analyzed data. FW and RN wrote the paper. 


\section{REFERENCES}

Ali T, Yoon GH, Shah SA, Lee HY, Kim MO. 2015. Osmotin attenuates amyloid beta-induced memory impairment, tau phosphorylation and neurodegeneration in the mouse hippocampus. Sci Rep 5, 11708. doi:10.1038/srep11708.

Autry AE, Adachi M, Nosyreva E, Na ES, Los MF, Cheng P, Kavalali ET, Monteggia LM. 2011. NMDA receptor blockade at rest triggers rapid behavioural antidepressant responses. Nature 475: 91-95.

Bliss TV, Collingridge GL. 1993. A synaptic model of memory: long-term potentiation in the hippocampus. Nature 361: 31-39.

Casillas-Espinosa PM, Powell KL, O'Brien TJ. 2012. Regulators of synaptic transmission: roles in the pathogenesis and treatment of epilepsy. Epilepsia 53: 41-58.

Chan KH, Lam KS, Cheng OY, Kwan JS, Ho PW, Cheng KK, Chung SK, Ho JW, Guo VY, Xu A. 2012. Adiponectin is Protective against Oxidative Stress Induced Cytotoxicity in Amyloid-Beta Neurotoxicity. PLoS One 7. doi:10.1371/journal.pone.0052354.

Chao N, Li ST. 2014. Synaptic and Extrasynaptic Glutamate Signaling in Ischemic Stroke. Curr Med Chem 21: 2043-2064.

Deng PY, Rotman Z, Blundon JA, Cho Y, Cui J, Cavalli V, Zakharenko SS, Klyachko VA. 2013. FMRP Regulates Neurotransmitter Release and Synaptic Information Transmission by Modulating Action Potential Duration via BK Channels. Neuron 77: 696-711.

Frankiewicz T, Potier B, Bashir ZI, Collingridge GL, Parsons CG. 1996. Effects of memantine and MK-801 on NMDA-induced currents in cultured neurones and on synaptic transmission and LTP in area CA1 of rat hippocampal slices. Br J Pharmacol 117: 689-697.

Ganguly K, Poo M. 2013. Activity-dependent neural plasticity from bench to bedside. Neuron 80: 729-741.

Gideons ES, Kavalali ET, Monteggia LM. 2014. Mechanisms underlying differential effectiveness of memantine and ketamine in rapid antidepressant responses. Proc Natl Acad Sci 111: 8649-8654.

Gleichmann M, Zhang Y, Wood WH 3rd, Becker KG, Mughal MR, Pazin MJ, van Praag H, Kobilo T, Zonderman AB, Troncoso JC, Markesbery WR, Mattson MP. 2012. Molecular changes in brain aging and Alzheimer's disease are mirrored in experimentally silenced cortical neuron networks. Neurobiol Aging 33 doi:10.1016

Gorska-Ciebiada M, Saryusz-Wolska M, Borkowska A, Ciebiada M, and Loba J. 2015. Adiponectin, leptin and IL-1 $\beta$ in elderly diabetic patients with mild cognitive impairment. Metab Brain Dis. doi:10.1007/s11011015-9739-0. 
Herron CE, Lester RA, Coan EJ, Collingridge GL. 1986. Frequency-dependent involvement of NMDA receptors in the hippocampus: a novel synaptic mechanism. Nature 322: 265-8.

Hoyda TD, Ferguson AV. 2010. Adiponectin modulates excitability of rat paraventricular nucleus neurons by differential modulation of potassium currents. Endocrinology 151: 3154-3162.

Hoyda TD, Samson WK, Ferguson A V. 2009. Adiponectin depolarizes parvocellular paraventricular nucleus Neurons controlling neuroendocrine and autonomic function. Endocrinology 150: 832-840.

Iannitti T, Graham A, Dolan S. 2015. Adiponectin-mediated analgesia and anti-inflammatory effects in rat. PLoS One 10, 1-13. doi:10.1371

Jeon BT, Shin HJ, Kim JB, Kim YK, Lee DH, Kim KH, Kim HJ, Kang SS, Cho GJ, Choi WS, Roh GS. 2009. Adiponectin protects hippocampal neurons against kainic acid-induced excitotoxicity. Brain Res Rev 61: 8188.

Kadowaki T, Yamauchi T, Kubota N, Hara K, Ueki K, Tobe K. 2006. Adiponectin and adiponectin receptors in insulin resistance, diabetes, and the metabolic syndrome. J Clin Invest 116: 1784-1792.

Kos K, Harte AL, da Silva NF, Tonchev A, Chaldakov G, James S, Snead DR, Hoggart B, O'Hare JP, McTernan PG, Kumar S. 2007. Adiponectin and resistin in human cerebrospinal fluid and expression of adiponectin receptors in the human hypothalamus. J Clin Endocrinol Metab 92: 1129-1136.

Kuenzi FM, Fitzjohn SM, Morton RA, Collingridge GL, Seabrook, GR .2000. Reduced long-term potentiation in hippocampal slices prepared using sucrose-based artificial cerebrospinal fluid. J Neurosci Methods 100: 117-122.

Kusminski CM, McTernan PG, Schraw T, Kos K, O'Hare JP, Ahima R, Kumar S, Scherer PE. 2007. Adiponectin complexes in human cerebrospinal fluid: Distinct complex distribution from serum. Diabetologia 50: 634642.

Lee EB, Warmann G, Dhir R, Ahima RS. 2011. Metabolic Dysfunction Associated with Adiponectin Deficiency Enhances Kainic Acid-Induced Seizure Severity. J Neurosci 31: 14361-14366.

Leo R, Di Lorenzo G, Tesauro M, Cola C, Fortuna E, Zanasi M, Troisi A, Siracusano A, Lauro R, Romeo F. 2006. Decreased plasma adiponectin concentration in major depression. Neurosci Lett 407: 211-213.

Li CF, Chen XM, Chen SM, Mu RH, Liu BB, Luo L, Liu XL, Geng D, Liu Q, Yi LT. 2016. Activation of hippocampal BDNF signaling is involved in the antidepressant-like effect of the NMDA receptor antagonist 7chlorokynurenic acid. Brain Res 1630: 73-82.

Li N, Lee B, Liu RJ, Banasr M, Dwyer JM, Iwata M, Li XY, Aghajanian G, Duman RS. 2010. mTOR-dependent synapse formation underlies the rapid antidepressant effects of NMDA antagonists. Science 329: 959-64.

Lohmann C, Kessels HW. 2014. The developmental stages of synaptic plasticity. J Physiol 592: 13-31.

Machado-Vieira R, Gold PW, Luckenbaugh DA, Ballard ED, Richards EM, Henter ID, De Sousa RT, Niciu MJ, Yuan $P$, Zarate CA. 2016. The role of adipokines in the rapid antidepressant effects of ketamine. Mol Psychiatry: $1-7$. 
Mandolesi G, Gentile A, Musella A, Fresegna D, De Vito F, Bullitta S, Sepman H, Marfia GA, Centonze D. 2015. Synaptopathy connects inflammation and neurodegeneration in multiple sclerosis. Nat Rev Neurol 11: 711-724.

Masaki T, Anan F, Shimomura T, Fujiki M, Saikawa T, Yoshimatsu H. 2012. Association between hippocampal volume and serum adiponectin in patients with type 2 diabetes mellitus. Metabolism 61: 1197-1200.

Mavroconstanti T, Halmøy A, Haavik J. 2014. Decreased serum levels of adiponectin in adult attention deficit hyperactivity disorder. Psychiatry Res 216: 123-130.

Mimee A, Smith PM, Ferguson AV. 2013. Circumventricular organs: Targets for integration of circulating fluid and energy balance signals? Physiol Behav 121: 96-102.

Monyer H, Burnashev N, Laurie DJ, Sakmann B, Seeburg PH. 1994. Developmental and regional expression in the rat brain and functional properties of four NMDA receptors. Neuron: 12: 529-540.

Musabak U, Demirkaya S, Genç G, llikci RS, Odabasi Z. 2010. Serum adiponectin, TNF- $\alpha$, IL-12p70, and IL13 levels in multiple sclerosis and the effects of different therapy regimens. Neuroimmunomodulation 18:57-66.

Narita K, Murata T, Takahashi, T, Kosaka H, Omata N, Wada Y. 2006. Plasma levels of adiponectin and tumor necrosis factor-alpha in patients with remitted major depression receiving long-term maintenance antidepressant therapy. Prog Neuro-Psychopharmacology Biol Psychiatry 30: 1159-1162.

Nishimura M, Izumiya Y, Higuchi A, Shibata R, Qiu J, Kudo C, Shin HK, Moskowitz MA, Ouchi N. 2008. Adiponectin prevents cerebral ischemic injury through endothelial nitric oxide synthase-dependent mechanisms. Circulation 117: 216-223.

Nosyreva E, Autry AE, Kavalali ET, Monteggia LM. 2014. Age dependence of the rapid antidepressant and synaptic effects of acute NMDA receptor blockade. Front Mol Neurosci 7: 94.

Okada-Iwabu, M, Iwabu M, Ueki K, Yamauchi T, Kadowaki T. 2015. Perspective of small-molecule AdipoR agonist for type 2 diabetes and short life in obesity. Diabetes Metab J. 39: 363-372.

Okada-Iwabu M, Yamauchi T, Iwabu M, Honma T, Hamagami K, Matsuda K, Yamaguchi M, Tanabe H, Kimura-Someya T, Shirouzu M, Ogata H, Tokuyama K, Ueki K, Nagano T, Tanaka A, Yokoyama S, Kadowaki T. 2013. A small-molecule AdipoR agonist for type 2 diabetes and short life in obesity. Nature 503: 493-9.

Popoli M, Yan Z, McEwen BS, Sanacora G. 2012. The stressed synapse: the impact of stress and glucocorticoids on glutamate transmission. Nat Rev Neurosci 13: 22-37.

Qi Y, Takahashi N, Hileman SM, Patel HR, Berg AH, Pajvani UB, Scherer PE, Ahima RS. 2004. Adiponectin acts in the brain to decrease body weight. Nat Med 10: 524-529.

Qiu G, Wan R, Hu J, Mattson MP, Spangler E, Liu S, Yau SY, Lee TM, Gleichmann M, Ingram DK, So KF, Zou S. 2011. Adiponectin protects rat hippocampal neurons against excitotoxicity. Age (Omaha) 33:155-165.

Repunte-Canonigo V, Berton F, Cottone P, Reifel-Miller A, Roberts AJ, Morales M, Francesconi W, Sanna PP. 2010. A potential role for adiponectin receptor 2 (AdipoR2) in the regulation of alcohol intake. Brain Res 1339: 11-7. 
Ribeiro PO, Tomé ÂR, Silva HB, Cunha RA, Antunes LM. 2014. Clinically relevant concentrations of ketamine mainly affect long-term potentiation rather than basal excitatory synaptic transmission and do not change paired-pulse facilitation in mouse hippocampal slices. Brain Res 1560: 10-17.

Rodriguez-Pacheco F, Martinez-Fuentes AJ, Tovar S, Pinilla L, Tena-Sempere M, Dieguez C, Castaño JP, Malagon MM. 2007. Regulation of pituitary cell function by adiponectin. Endocrinology 148: 401-410.

Sasaki 1, Kawano T, Saito T, Yuzawa M, Saito T, Ikoma A, Tamemoto H, Kawakami M, Ishikawa SE. 2007. Hypoadiponectinemia in patients with cerebral infarction: comparison with other atherosclerotic disorders. Am J Med Sci 333: 140-144.

Scherer PE, Williams S, Fogliano M, Baldini G, Lodish HF (1995). A novel serum protein similar to C1q, produced exclusively in adipocytes. J Biol Chem 270: 26746-26749.

Shah SA, Lee HY, Bressan RA, Yun DJ, Kim MO. 2014. Novel osmotin attenuates glutamate-induced synaptic dysfunction and neurodegeneration via the JNK/PI3K/Akt pathway in postnatal rat brain. Cell Death Dis 5 : e1026. doi:10.1038

Song W, Huo T, Guo F, Wang H, Wei H, Yang Q, Dong H, Wang Q, Xiong L4. 2013. Globular adiponectin elicits neuroprotection by inhibiting NADPH oxidase-mediated oxidative damage in ischemic stroke. Neuroscience 248:136-144.

Tanabe H, Fujii Y, Okada-Iwabu M, Iwabu M, Nakamura Y, Hosaka T, Motoyama K, Ikeda M, Wakiyama M, Terada T, Ohsawa N, Hato M, Ogasawara S, Hino T, Murata T, Iwata S, Hirata K, Kawano Y, Yamamoto M, Kimura-Someya T, Shirouzu M, Yamauchi T, Kadowaki T, Yokoyama S. 2015. Crystal structures of the human adiponectin receptors. Nature 520: 312.

Teixeira AL1, Diniz BS, Campos AC, Miranda AS, Rocha NP, Talib LL, Gattaz WF, Forlenza OV. 2013. Decreased levels of circulating adiponectin in mild cognitive impairment and alzheimer's disease. NeuroMolecular Med 15: 115-121.

Thundyil J, Pavlovski D, Sobey CG, Arumugam TV. 2012. Adiponectin receptor signalling in the brain. Br J Pharmacol 165: 313-327.

Vuolteenaho K, Leppänen T, Kekkonen R, Korpela R, Moilanen E. 2014. Running a Marathon Induces Changes in Adipokine Levels and in Markers of Cartilage Degradation - Novel Role for Resistin. PLoS One 9: e110481. doi:10.1371.

Waki H, Yamauchi T, Kamon J, Kita S, Ito Y, Hada Y, Uchida S, Tsuchida A, Takekawa S, Kadowaki T. 2005. Generation of globular fragment of adiponectin by leukocyte elastase secreted by monocytic cell line THP1. Endocrinology 146: 790-796.

Wang ZV, Scherer, PE. 2016. Adiponectin, the past two decades. J Mol Cell Biol doi:10.1093

Wen JP, Lv WS, Yang J, Nie AF, Cheng XB, Yang Y, Ge Y, Li XY, Ning G. 2008. Globular adiponectin inhibits GnRH secretion from GT1-7 hypothalamic GnRH neurons by induction of hyperpolarization of membrane potential. Biochem Biophys Res Commun 371: 756-761.

Yamauchi T, Kadowaki T. 2013 . Adiponectin receptor as a key player in healthy longevity and obesityrelated diseases. Cell Metab. 17: 185-196. 
Yamauchi T1, Nio Y, Maki T, Kobayashi M, Takazawa T, Iwabu M, Okada-Iwabu M, Kawamoto S, Kubota N, Kubota T, Ito Y, Kamon J, Tsuchida A, Kumagai K, Kozono H, Hada Y, Ogata H, Tokuyama K, Tsunoda M, Ide T, Murakami K, Awazawa M, Takamoto I, Froguel P, Hara K, Tobe K, Nagai R, Ueki K, Kadowaki T. 2007. Targeted disruption of AdipoR1 and AdipoR2 causes abrogation of adiponectin binding and metabolic actions. Nat Med 13: 332-339.

Yau SY, Li A, Hoo RL, Ching YP, Christie BR, Lee TM, Xu A, So KF. 2014. Physical exercise-induced hippocampal neurogenesis and antidepressant effects are mediated by the adipocyte hormone adiponectin. Proc Natl Acad Sci U S A. 111: 15810-5.

Zhang D, Wang X, Lu XY. 2016a. Adiponectin exerts neurotrophic effects on dendritic arborization, spinogenesis and neurogenesis in the dentate gyrus in male mice. Endocrinology 157:2015-2078.

Zhang D, Wang X, Wang B, Garza JC, Fang X, Wang J, Scherer PE, Brenner R, Zhang W, Lu XY. 2016b. Adiponectin regulates contextual fear extinction and intrinsic excitability of dentate gyrus granule neurons through AdipoR2 receptors. Mol Psychiatry: 1-12.

Zucker RS, Regehr WG. 2002. Short-Term Synaptic Plasticity. Annu Rev Physiol 64: 355-405. 
Figure legends

Figure 1. Effects of different concentrations of Adiporon (ADPO; 1.5, 3, $30 \mu \mathrm{M}$ ) on PPR and input-output relationship

A,B, PPR induced by pairs of stimulation delivered at several interstimulus intervals $(20,50,100,200,300$, $500 \mathrm{~ms})$. Data are presented as mean \pm SEM. Young group $(A), n=5-6$ for each ADPO concentration from six mice; and adult group (B), $n=5-6$ for each ADPO concentration from six mice. ${ }^{*} p<0.05$ vs. the vehicle group.

$C, D$, Input-output relationship of fEPSPs as a function of presynaptic fiber volley size at the Schaffer collateral/CA1 pyramidal cell synapses. Young group (C), $n=5-6$ separate recordings for each concentration from five mice; and adult group (D), $n=5-6$ for each concentration from six mice. No significant difference was observed between ADPO and vehicle-treated slices.

Figure 2. Effects of different concentrations of Adiporon (ADPO; 1.5, 3, $30 \mu \mathrm{M}$ ) on CA1-LTP and on fEPSPs during tetanus

A,B,LTP induced by high frequency stimulation (HFS; $100 \mathrm{~Hz}, 1 \mathrm{sec}$ ) delivered at Schaffer collaterals. Sample traces (above) and summary graph (below) of the averaged time course of LTP. Data are presented as mean \pm SEM. Young group (A), $n=5-7$ for each ADPO concentration from nine mice; adult group (B), $n=7-9$ for each ADPO concentration from nine mice. ${ }^{*} p<0.05$ vs. the vehicle group ; ${ }^{*} p<0.01$ vs. the vehicle group.

C, fEPSP during tetanus in the adult group. Sample traces (above) show fEPSP during tetanus in the vehicle group (left) vs. pre-incubated slice (ADPO, $30 \mu \mathrm{M}$ ) (right). Bar graph (below) representing the overall depolarization during tetanus as AUC normalized to the first fEPSP in each train at increasing ADPO concentrations. $n=7-9$ for each concentration from nine mice. ${ }^{*} \mathrm{p}<0.05$ vs. the vehicle group; ${ }^{* *} \mathrm{p}<0.01$ vs. the vehicle group. ${ }^{* * *} p<0.001$ vs. the vehicle group. 

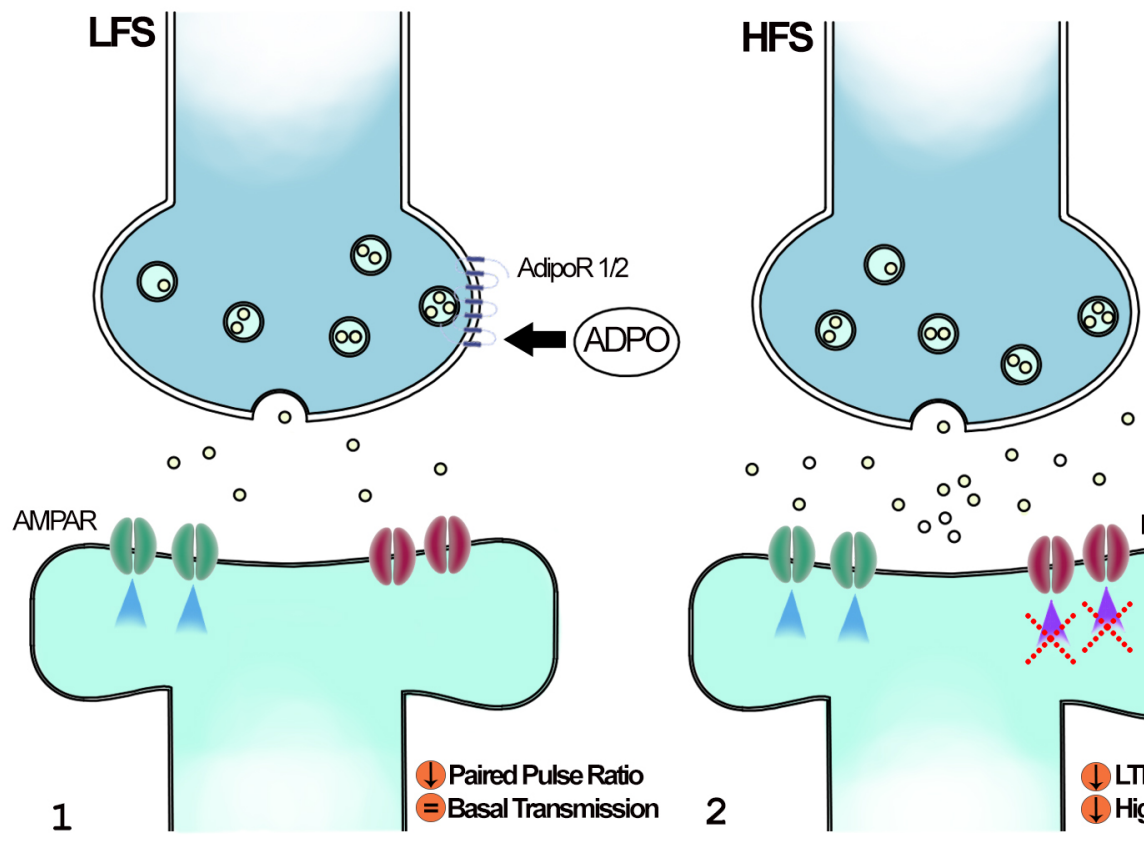

AdipoR $1 / 2$

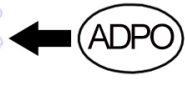


A

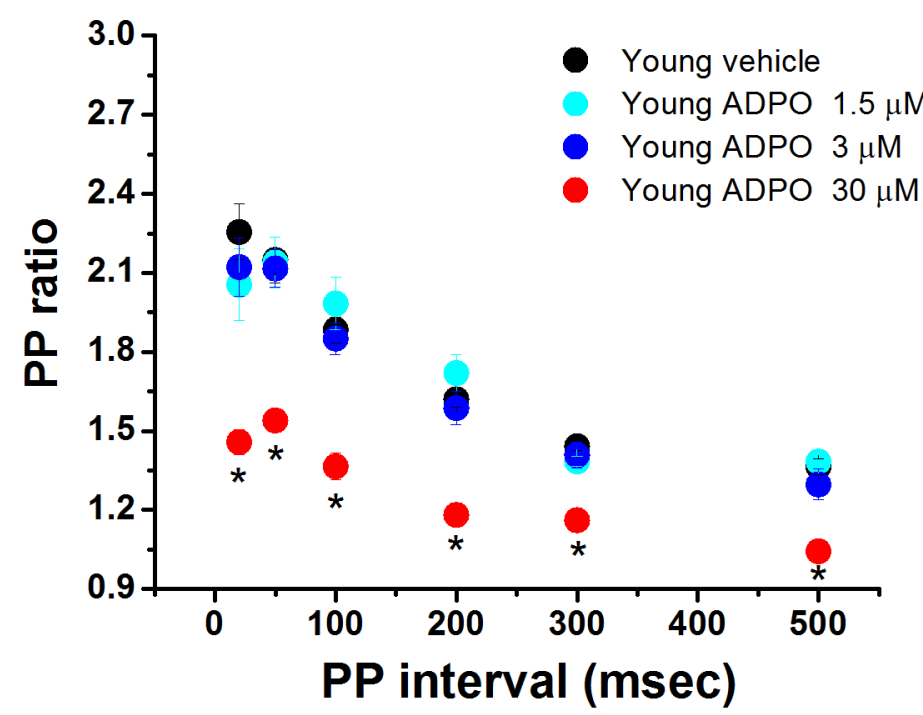

C

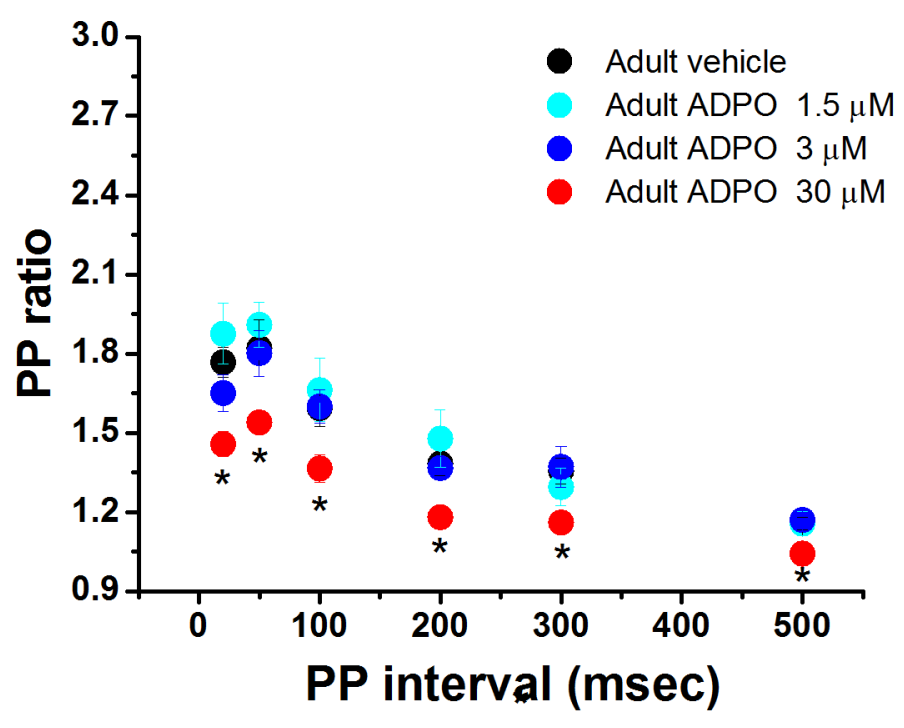

B

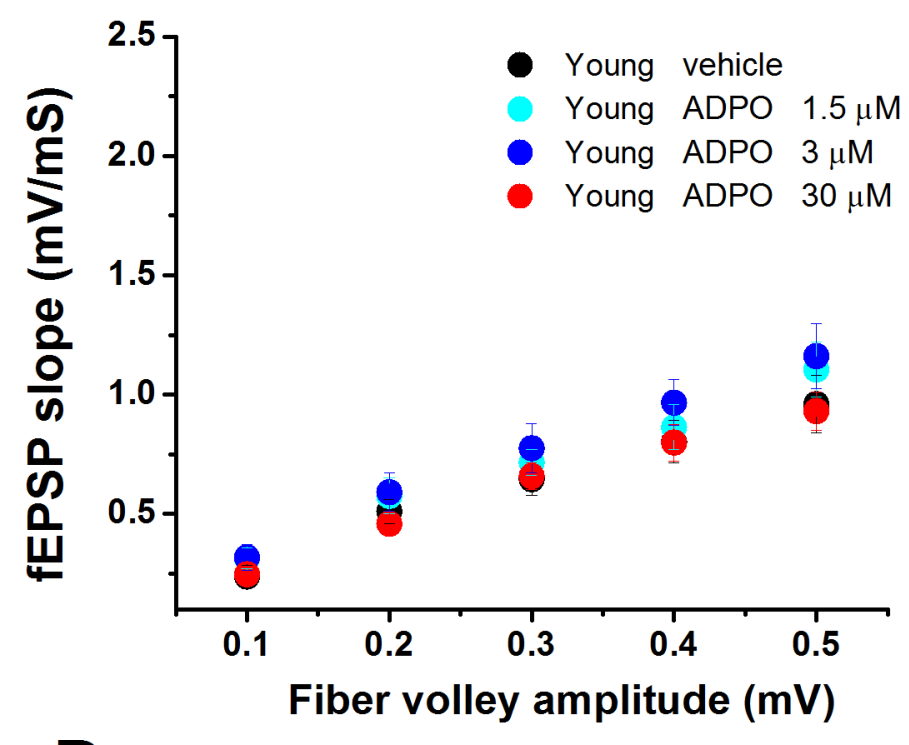

D

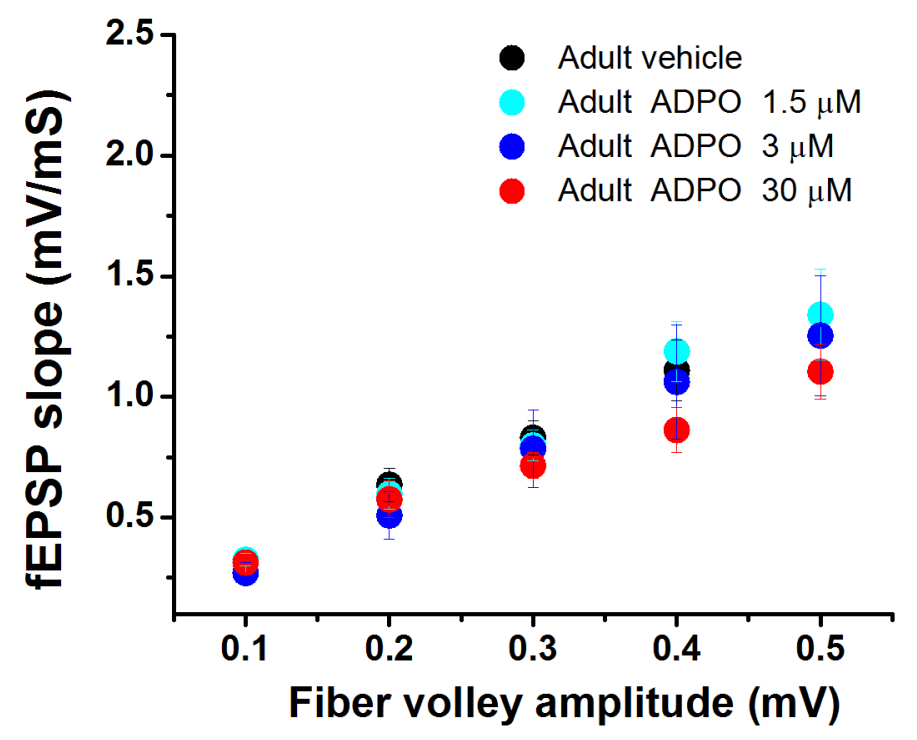


A
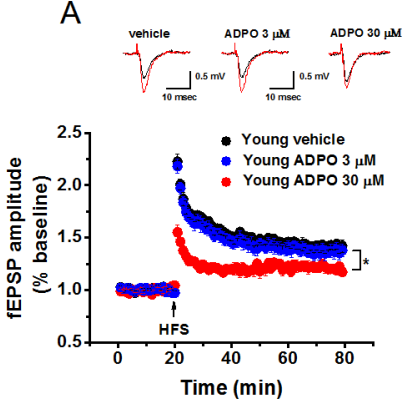

B
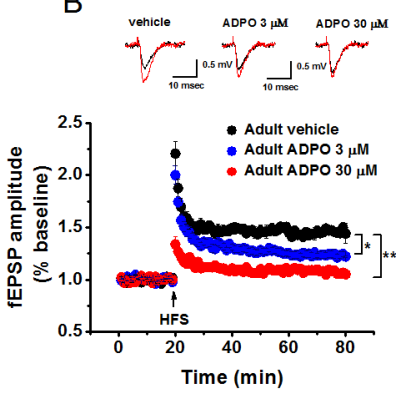

C Adult vehicle Adult ADPO $30 \mu \mathrm{M}$
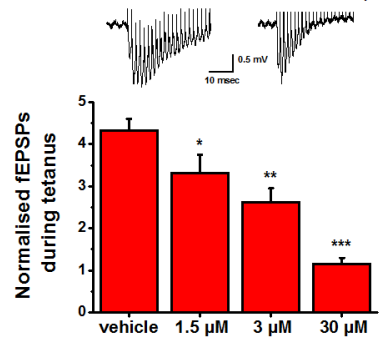